Int. J. Electrochem. Sci., 13 (2018) $8518-8529$

\title{
Self-assembled Diphenylalanine Peptide Fibrils with Ultra-High Aspect Ratio: A Platform for Sensitive Electrochemical $\mathrm{H}_{2} \mathrm{O}_{2}$ Sensor
}

\author{
Yuehong Pang, Qiufang Zhang, Xiulan Sun, Jian Ji, Fuwei Pi, Xiaofang Shen*
}

State Key Laboratory of Food Science and Technology, School of Food Science and Technology, Jiangnan University, Wuxi, 214122, China

*E-mail: xfshen@jiangnan.edu.cn

doi: $10.20964 / 2018.09 .15$

Received: 3 May 2018 / Accepted: 6 June 2018 / Published: 5 August 2018

Inspired from the pathogenic process of diphenylalanine (FF) self-assembly, a key structural motif in forming Alzheimer's $\beta$-amyloid peptide fibrils, a facile way for preparation of FF aromatic dipeptide fibrils and fabrication of an electrochemical biosensor were developed. Long persistence length FF fibrils with ultra-high aspect ratio over 1000 were obtained using cationic surfactant assisted evaporation induced self-assembly. The Cotton effects indicate a signature of dominant $\beta$-sheet arrangement and the thickness of the $\beta$-sheet monolayer is estimated to be $2.38 \mathrm{~nm}$. The obvious blueshift of intrinsic fluorescence indicates an extended $\mathrm{H}$-aggregate between the phenyl rings in a parallel mode. The FF fibrils based electrochemical biosensor, taking horseradish peroxidase as a model enzyme, displayed an excellent electrocatalytic activity to the reduction of $\mathrm{H}_{2} \mathrm{O}_{2}$. The peak current was a linear function of concentrations ranging from $7.5 \times 10^{-7}$ to $1.4 \times 10^{-5} \mathrm{M}$, with a detection limit of $2.5 \times 10^{-7} \mathrm{M}$. The apparent Michaelis-Menten constant was $7.2 \mu \mathrm{M}$. These results indicate that the FF fibrils with ultra-high aspect ratio providing a new and promising platform for construction of electrochemical biosensors.

Keywords: Diphenylalanine; Aromatic dipeptide; Self-assembly; Nanofibrils; Electrochemical Biosensor

\section{FULL TEXT}

(C) 2018 The Authors. Published by ESG (www.electrochemsci.org). This article is an open access article distributed under the terms and conditions of the Creative Commons Attribution license (http://creativecommons.org/licenses/by/4.0/). 